\title{
Particle agglomeration in sheared fluids
}

\author{
David Dogon • Michael Golombok
}

Received: 18 December 2013/Accepted: 5 May 2014/Published online: 25 May 2014

(C) The Author(s) 2014. This article is published with open access at Springerlink.com

\begin{abstract}
Orthokinetic agglomeration is a candidate mechanism for selectively increasing proppant size in large fractures during subsurface flow. The rate of agglomeration shows a maximum at shear rates of $275 \mathrm{~s}^{-1}$ suggesting that the ability to selectively grow particles depends on the hydrodynamics. Growth rates are shown to increase with increasing ion availability per unit surface area. The availability of solution ions and the average shear rates are the key parameters determining agglomeration. Precipitated species act as bridging "glue" between particles. Reduced growth rates are found for higher particle concentrations and also for larger particle size. This result has possible applications for shear-selective mechanical blocking which can be applied to solve the problem of high conductivity paths in fractured reservoirs for both traditional oil recovery as well as geothermal heat mining from fractured basement.
\end{abstract}

Keywords Fracture flow · Proppants · Blocking · Agglomeration · Shear

\section{List of symbols \\ d Particle diameter \\ D Impeller diameter \\ $h \quad$ Fracture aperture \\ $k$ Agglomeration rate constant}

D. Dogon $(\bowtie) \cdot$ M. Golombok

Faculty of Mechanical Engineering, Technische Universiteit Eindhoven, Den Dolech 2, 5600 MB Eindhoven,

The Netherlands

e-mail: d.dogon@tue.nl

D. Dogon · M. Golombok

Shell Global Solutions International B.V., Kessler Park 1, 2288 GS Rijswijk, The Netherlands

$\begin{array}{ll}n & \text { Number density in size class } \\ N & \text { Total number density } \\ N_{\mathrm{P}} & \text { Power number } \\ P & \text { Pressure } \\ r & \text { Rate } \\ w & \text { Wall } \\ x & \text { Fracture axis }\end{array}$

\section{Greek}

$\alpha \quad$ Supersaturation rate

$\beta$ Collision rate constant

$\gamma \quad$ Shear rate

$\mu \quad$ Viscosity

$\phi \quad$ Sticking frequency

$\Omega \quad$ Stirrer speed

\section{Subscripts}

agg Aggregation

col Collision

$N \quad$ Average overall particle sizes

\section{Introduction}

Particle suspensions in fluids are used in various aspects of petroleum production. These include drilling muds in wells and proppants in fractures. The latter category includes a number of options for various stages of the production process. Currently the best known application is in unconventional gas where the role of particles is to keep fractures open following high-pressure hydraulic fracturing. In oil recovery the problem is pre-existing rather than stimulated fractures, which provide a high conductivity path for secondary production injected water to break through to the producer well. This limits the amount of oil that can be swept in the permeable matrix. In this case 
proppants are used to reduce leak-off via fractures. The same effects are also observed in enhanced geothermal systems where following stimulation it is desirable to block high conductivity paths (i.e. large fractures) so that the heat is more efficiently extracted (Brown et al. 1999).

The common element in all these applications is the introduction of small particles suspended in the injection water. Proppant materials are pumped in suspensions into fractured unconventional shale gas reservoirs to prop open fractures and maintain conductivity (Smith and Shlyapubersky 2000). Silica micro-particles are introduced in fractured oil reservoirs to block pores and reduce fluid leak-off. In oil reservoirs larger fractures divert a disproportionately large amount of the injected water and prevent efficient matrix penetration and permeable reservoir sweep. These fluid diversions are known as subsurface "shortcircuits". They are also a feature of fractured enhanced geothermal systems. Most geothermal reservoirs occur in fractured basement such as granite where permeable flow is impossible. Short circuits mean that heat is not efficiently recovered, and high flows of unheated water are obtained rather than a smaller flow with higher quality heat.

In both oil and geothermal cases, fluid diversion thus results in non-optimal use of the energy resource stored in the reservoir (Chilingarian et al. 1989). Managing such short-circuits becomes a significant challenge for reservoir engineers and operators. The classic reservoir techniques for fracture shut-off applied to oil/gas reservoirs, such as cementing or polymer injection, have the problem that they are not fracture-size selective (Schechter 1992).

In this paper, we explore the application of orthokinetic agglomeration of particles which could be used to selectively shut off larger fractures. This lowers fluid losses by fracture leak-off and could also be applied to selectively increase proppant size in large fractures. We couple a flow characteristic of large fractures to cause selective material blocking in them and not in small fractures. The questions are: (1) are the shear rates at which this agglomeration occurs relevant for subsurface flow of injected fluids and (2) what are the rates and are they fast enough? "Background" outlines the physical processes we seek to exploit. An experimental description follows in "Experiment" and the results are discussed and analysed in "Results and discussion".

\section{Background}

In a reservoir with fractured connectivity there are a multitude of fractures and none of them will be simple singledimensioned conductive routes. Nevertheless, the size selective shut-off problem can be reduced conceptually to a comparison of a small and large fracture pair extending

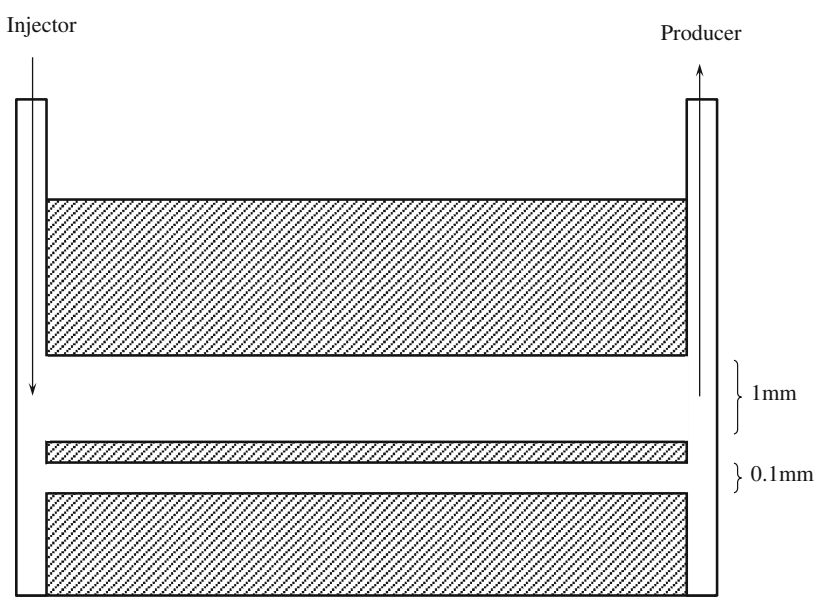

Fig. 1 Schematic of dual fracture system for competitive flow in fractured connectivity systems

between injector and producer. The basic principle of a low and high resistance path can thus be represented as in Fig. 1. There is a fixed pressure drop between the two ends of the fracture network- the injection well at one end and the producer at the other. If the large fracture aperture is 10 times that of the small fracture, then 1,000 times as much water passes through the large fracture compared to the small one due to the cubic dependence of flow rate on fracture height given by the Hagen-Poiseuille relationship. In a hydrocarbon reservoir, injected water is diverted away from optimally sweeping the reservoir permeable zones and driving oil through the porous matrix to the production well (Zimmerman and Bodvarsson 1996).

In the oil reservoir we need a fluid property related to the fracture size which can be coupled to particle growth. Such a property is the fluid shear to which two properties can be coupled:

- The shear is proportional to fracture width and therefore is larger in large fractures than in smaller ones.

- Suspensions of small particles agglomerate faster under high shear conditions in the process of "orthokinetic agglomeration".

The first observation follows from the Hagen-Poiseuille equation. For flow within fractures the shear rate at the wall $\gamma_{w}$ is determined by the fracture aperture height $h$ and the pressure drop $d P$ between the injection and producer wells separated by a distance $d x$,

$\gamma_{W}=\frac{h}{2 \mu} \frac{d P}{d x}$

The second observation relates to shear-induced agglomeration processes. In general, particle agglomeration can be attributed to two physical causes. Brownian motion results in isokinetic agglomeration which is shear independent. In orthokinetic agglomeration, 
particle collision rates increase with shear: at higher shear rates, layers of fluid (with suspended particles), move faster past one another (Elimelech et al. 1995). Equation 1 shows that the shear is larger in larger fractures. Orthokinetic processes thus have potential to mechanically block or narrow larger fractures selectively because of the faster agglomeration processes in them due to larger shear. This applies to both particles agglomerating with each other or agglomerating with the fracture wall.

Smoluchowski (1917) first described the rate of collision as dependent on the shear rate $\gamma$, particle number concentration $n$ for particle $i$ and $j$, respectively, and particle size $d$ :

$r_{\mathrm{col}}=\beta_{i j} n_{i} n_{j}$,

where the collision rate constant $\beta_{i j}$, between particle $i$ and $j$, is given by:

$\beta_{i j}=\frac{1}{6}\left(d_{i}+d_{j}\right)^{3} \gamma$

Not every collision leads to an agglomeration event, the rate at which two colliding particles ( $i$ and $j$ ) agglomerate is therefore different from the collision rate:

$r_{\text {agg }}=k_{i j} n_{i} n_{j}$

The fraction of collisions which lead to agglomeration (either with another particle or with a wall) is defined by the sticking frequency, $\phi$,

$\phi=\frac{r_{\text {agg }}}{r_{\text {col }}}$

The validity of this theory has been investigated both numerically and experimentally (Balakin et al. 2012; Yates et al. 2008) and has been shown to describe the relationship between particle growth and collision rates. At moderate shear rates this dependence is linear (Eq. 3), however, at high shear rates where tensile forces are large, particle disruption occurs resulting in breakup and reduced agglomeration rates, which ultimately fall to zero (Hollander et al. 2003; Colomer et al. 2005). Mumtaz and Hounslow (2000) showed that for batch and continuous experiments of the crystallization and growth of calcium oxalate, the agglomeration rate constant which best fits the data is particle size-independent. This convenient finding allows the agglomeration rates described in Eq. 4 to be simplified in terms of $N$, the total particle concentration, as follows:

$r_{\text {agg }}=\frac{1}{2} k_{N} N^{2}$

Furthermore, Mumtaz et al. (1997) employed this simplification to develop a model to quantify agglomeration rate constants. Using the same assumptions, the collision rate constant $\beta$ can be estimated using the average particle diameter for the size-independent system and is given by a simplification of Eq. 3 for the monodisperse case:

$\beta_{N}=\frac{4}{3} \bar{d}^{3} \bar{\gamma}$

The size-independent agglomeration rate constant $k_{N}$ and collision rate constant $\beta_{N}$ can therefore be related through total number concentration and mean particle diameter-which can be determined experimentally.

These are all physical effects. However, the final result is dependent on the sticking efficiency and this is a largely chemical effect. It is determined by solution ionic strength and counterion supersaturation (Mumtaz and Hounslow 2000; Ilievski and Livk 2006; Livk and Ilievski 2007). Whereas shear forces promote collisions, it is the interaction energy that determines sticking between particles. The ionic nature of the solution influences these forces: ions determine the surface charge and the ability of free ions to shield surfaces charges. Mumtaz and Hounslow (2000) describe supersaturation as providing a "bridging cement" between particles upon collision due to the precipitation of mineral salts on the surface. Since the degree of supersaturation directly influences the rate of precipitation, the sticking efficiency is expected to be positively correlated with it. Huang et al. (1991) showed that in $\mathrm{CaCO}_{3}$ suspensions $\mathrm{Ca}^{2+}$ ions were the zeta potential determining ion-ions that are free to move from the surface to the bulk solution-and that surface charge increased with increased $\mathrm{Ca}^{2+}$ concentration. They also showed that increases in surface charge resulted in increased particle-particle repulsion and reduced agglomeration. Rashchi et al. (1998) showed that $\mathrm{Ca}^{2+}$ adsorption on silica was again the zeta potential determining ion. However, in the presence of carbonate ions, $\mathrm{CaCO}_{3}$ is precipitated, suggesting the importance of supersaturation and precipitation as a way to overcome the effects of high $\mathrm{Ca}^{2+}$ adsorption and high surface charges. Our experiments examine a combination of the features above, in order to assess applicability to the subsurface fracture environment.

\section{Experiment}

\section{Stirred cell}

Inside a fracture, there is a distribution of shear rates present. Shear is actually a tensor rather than vector quantity and Eqs. 3 and 7 refer to the absolute magnitude of the shear. The smallest value is $\gamma=0$ in the middle of the fracture. Referring to the fracture pair Fig. 1, then for a pressure gradient of $10 \mathrm{mbar} / \mathrm{m}$ in a $1 \mathrm{~mm}$ fracture, the wall shear is $500 \mathrm{~s}^{-1}$ with an average of $250 \mathrm{~s}^{-1}$. 
Similarly there is a distribution of shear rates present in stirred cells which are used in this study to shear fluids containing suspended particles. In a stirred cell, the stirrer speed, $\Omega$, is used to vary the average shear rate according to (Sanchez Perez et al. 2006):

$\bar{\gamma}=\sqrt{\frac{4 N_{\mathrm{P}} \rho D^{2} \Omega^{3}}{\pi \mu}}$,

where $N_{\mathrm{P}}$ is the power number, $D$ is the paddle diameter, $\Omega$ the stirrer speed and $\mu$ is the fluid viscosity. This expression for shear rate is derived from the total energy dissipation rate. Spatial averages will bias the results, and the shear experienced by particles will differ between their positions in the cell (Hollander et al. 2003). Errors due to concentration gradients in the stirred cell can be overcome by sampling from numerous points in the batch system.

Batch tests in a stirred cell provide a controlled environment to study particle systems maintained in suspension. The tests were performed in a glass cylindrical cell of diameter $100 \mathrm{~mm}$ and height $140 \mathrm{~mm}$ with a square stirrer paddle of $85 \mathrm{~mm} \times 85 \mathrm{~mm}$, providing a well-defined average shear rate. Particles were first sheared in deionised water at a rate of $1,800 \mathrm{~s}^{-1}$ for $1 \mathrm{~h}$ to break up existing agglomerates and were then measured for size. After this, particles were sheared for $8 \mathrm{~h}$ at 100, 150, 200, 275 and $500 \mathrm{~s}^{-1}$ with an IKA-WERKE Eurostar digital electric stirrer. Experiments were carried out under laminar conditions as determined by Reynolds numbers for stirred tanks.

\section{Materials}

Polydisperse industrial grade $\mathrm{CaCO}_{3}$ particles ("Baracarb") were obtained from Halliburton Europe in size classes with volume median diameters of 2, 5 and $25 \mu \mathrm{m}$. (The number given after the name "Baracarb" designates the size class based on this median diameter.) The particles are produced from ground marble, resist size reduction beyond their specified range and have a specific gravity of $2.7 \mathrm{~g} / \mathrm{cm}^{3}$. They were chosen because of existing application in the oil and gas industry.

Reagent grade $\mathrm{CaCl}_{2}$ and $\mathrm{Na}_{2} \mathrm{CO}_{3}$ provided by Sigma Aldrich were used to make up two $4.2 \mathrm{mM}$ solutions which were then added to the particle suspension to obtain the required degree of $\mathrm{Ca}^{2+}$ and $\mathrm{CO}_{3}{ }^{2-}$ supersaturation $\alpha$ defined by.

$\alpha=\frac{\left[\mathrm{Ca}^{2+}\right]_{\mathrm{SS}} \times\left[\mathrm{CO}_{2}^{2-}\right]_{\mathrm{SS}}}{\left[\mathrm{Ca}^{2+}\right]_{\mathrm{Eq}} \times\left[\mathrm{CO}_{2}^{2-}\right]_{\mathrm{Eq}}}$

The solubility product in water at equilibrium is $K_{\mathrm{sp}}=5 \times 10^{-9}$ giving a nominal solubility of $7 \times 10^{-5}$ mol/l. Final solutions were therefore made up to $\alpha=5,10$ and 20 times this concentration and preliminary tests showed that no spontaneous nucleation and precipitation occurred. These solutions were then sheared for $8 \mathrm{~h}$. In this way, the effect of low and high shear rates on agglomeration under different conditions of ionic concentration, particle concentration and particle size was investigated.

Particle size analysis

Particle size was measured using a Galai CIS-100 Particle sizer. A rotating prism scans a laser beam across the particle suspension. As the laser beam encounters a particle, the beam is obscured for a time and measured by a detector. The time of obscuration is measured and since the rotary speed of the laser is known, the particle diameter can be determined using the Laser Obscuration Time (LOT) principle (Moes and Flash 2013). Due to direct particle size measurement, in comparison to other optical techniques, LOT is independent of material optical properties and solution chemistry. The technique also does not assume spherical particles. Particle sizes can be measured in the range $0.1-300 \mu \mathrm{m}$ and data are analysed for particle size distribution, number (NMD) and volume (VMD) mean diameters and particle concentration. Samples were taken every $2 \mathrm{~h}$ and analysed in duplicate for size distribution.

Our analysis is based on Eq. 6. Integrating over the time of shearing we obtain:

$\frac{1}{N_{t}}-\frac{1}{N_{\text {initial }}}=\frac{1}{2} k_{N} t$

Since the initial and final particle concentrations as well as the average particle size are measured and the time known, we can calculate the average agglomeration rate, $k_{N}$ from Eq. 10 and $\beta_{N}$ from Eq. 7. Using the empirical values for $k_{N}$ and $\beta_{N}$ the sticking efficiency can be obtained from Eq. 4.

\section{Results and discussion}

Growth and distribution

Since the aim of this study was to apply particle agglomeration in water or brines of similar carrying power, it was important to first test the fluid's suspension ability at the required shear rates. Initial visual tests showed Baracarb-2 and -5 to be maintained in suspension even at the lowest shear rates. Baracarb-25 settled out at shear rates below $275 \mathrm{~s}^{-1}$ - a critical value for characterising behavioursee below. As a result these large particles were excluded from further investigation in this study as we only deal here with aqueous carrying power as outlined above. The 


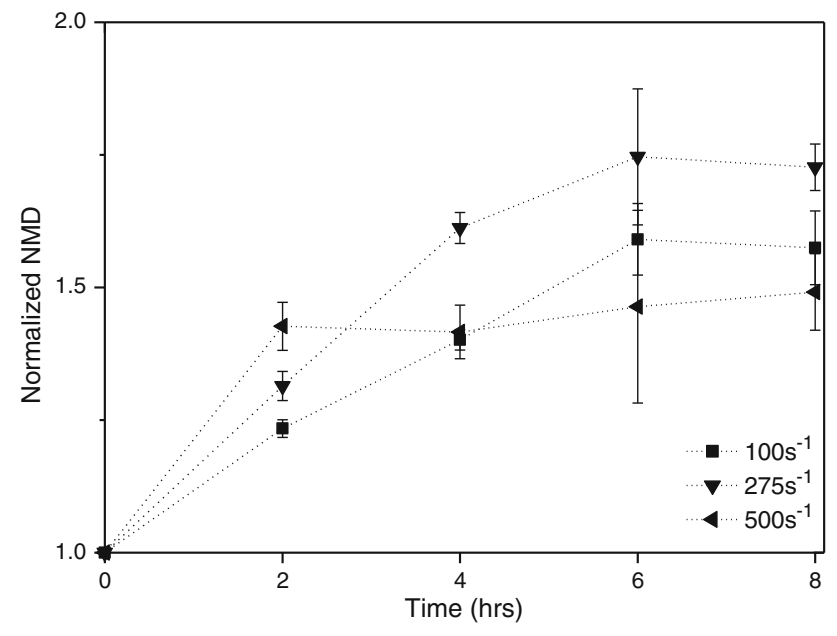

Fig. 2 Particle agglomeration for Baracarb-5 at initial concentration of $0.25 \mathrm{~g} / \mathrm{l}$ and solution supersaturation $\alpha=10$

suspension ability of the fluid is governed by factors that include viscosity, particle size, and fluid velocity. There is therefore potential for applications of larger particles at higher shear rates or viscosified aqueous media. This is the focus of future research and is not germane to the study described here which focuses on small particle shearinduced agglomeration potential in water-like media, i.e. aqueous viscosities.

Figure 2 shows particle size evolution for Baracarb-5 over $8 \mathrm{~h}$ for three shear rates tested in the stirred cell. Results are reported as a normalized number mean diameter (NMD), $\bar{d}(t) / \bar{d}(0)$, since it is the number of particles on which the agglomeration equation is based rather than for example other standards such as volume or Sauter mean diameters. The initial rates over the first $0-2 \mathrm{~h}$ support Smoluchowski's theory where the $500 \mathrm{~s}^{-1}$ shear case has the highest initial growth and $100 \mathrm{~s}^{-1}$ the lowest. Increase in size is also a linear function of shear rate at this stage. These rates decrease as the solution becomes less saturated and other disruptive mechanisms develop. This growth rate decrease is seen most notably for the highest shear case, $500 \mathrm{~s}^{-1}$, where rapid growth over the first $2 \mathrm{~h}$ falls to nearly zero equilibrating at 1.5 times initial size-the lowest value for all cases tested. This is because larger agglomerates are unstable as high shearing forces break them apart.

For all cases, final particle size did not exceed 2 times the initial number mean diameter. This indicates that the smaller rather than larger particles in the size distribution agglomerate. This is supported by Fig. 3 which shows a particle size distribution for Baracarb-5 before and after shearing at $275 \mathrm{~s}^{-1}$ for $8 \mathrm{~h}$. The initial size distribution is unimodal with a second peak developed after shearing. The initial peak, centred on $1 \mu \mathrm{m}$, is reduced, indicating a significant reduction in the number of particles in the

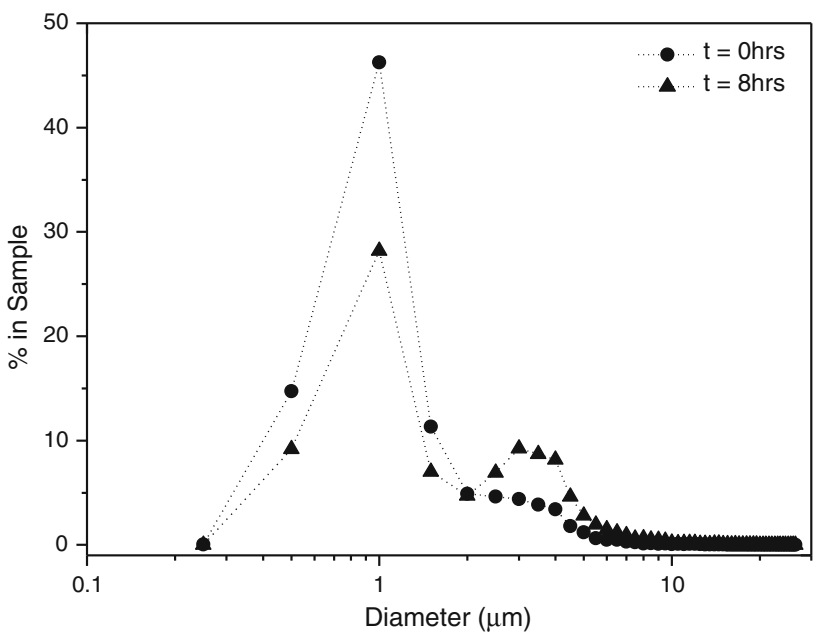

Fig. 3 Particle size distribution for $0.25 \mathrm{~g} / \mathrm{l}$ of Baracarb- 5 before and after shearing for $8 \mathrm{~h}$ at $\alpha=10$ and $\gamma=275 \mathrm{~s}^{-1}$

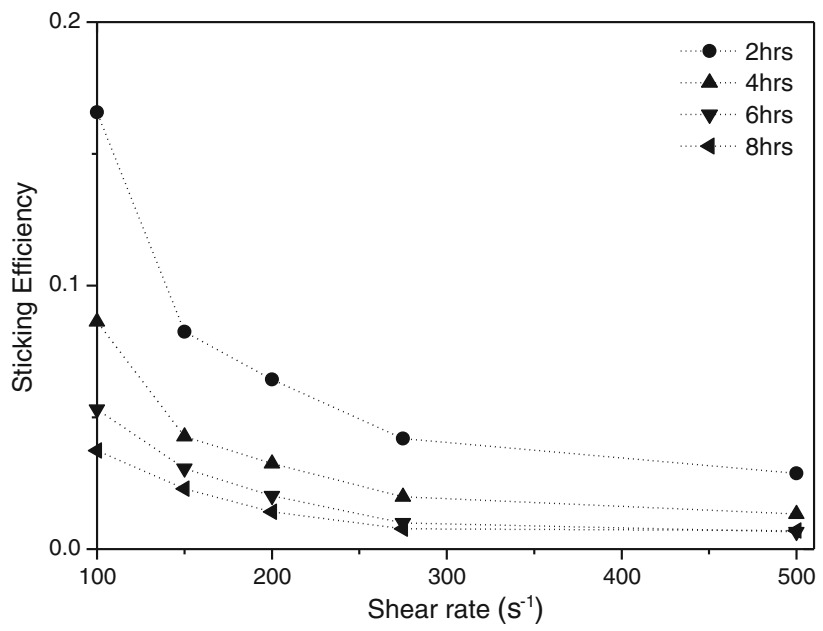

Fig. 4 Sticking efficiency as a function of shear rate $\gamma$ for different time durations of test

smaller size classes. The percentage of particles above $5 \mu \mathrm{m}$ remains relatively unchanged suggesting that the second peak is composed of agglomerates of the smaller particles.

\section{Sticking probability}

The sticking efficiency $\phi$ (Eq. 5) can be calculated by comparing the measured agglomeration rate (Eq. 6) and predicted shear-induced collision rate (Eq. 7). Figure 4 shows that the sticking efficiency $\phi$, i.e. the ratio of observed mean agglomeration to orthokinetic collision rate derived from Eq. 4, is negatively affected by fluid shear and the duration thereof. These results agree with Mumtaz and Hounslow (2000) in so far that the number of collisions resulting in sticking is much lower than predicted and 


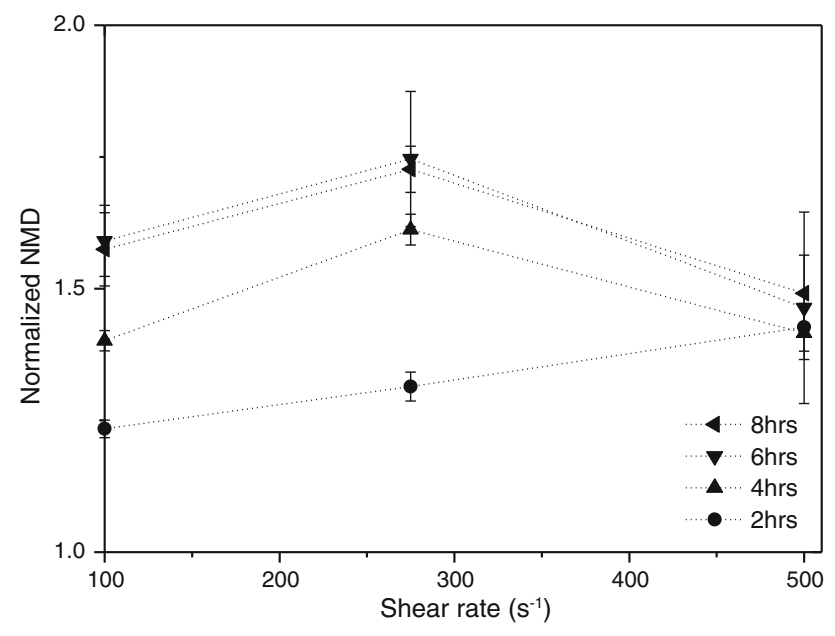

Fig. 5 Normalized number mean diameter at different shear rates and experimental time for $0.25 \mathrm{~g} / \mathrm{l}$ of Baracarb-5 at $\alpha=10$

decreases for increasing shear. This can be explained by hydrodynamic forces and collision contact time having a significant effect in maintaining a newly formed "doublet" of two sticking particles. For higher shear, contact time is reduced and sufficient precipitation cannot occur. In addition, the strength of the bond depends on bridging chemistry and electrostatic forces (Hounslow and Andreassen 2004) and, as time elapses, bridging ions are depleted. The sticking efficiency decreases with shear rate (Fig. 4) but also decreases with the time duration of shearing.

Even though sticking efficiency decreases with increasing stirrer speed, we still observe increasing growth as predicted by Smoluchowski. Figure 5 shows particle NMD versus shear rate at different experimental times. Over the first $2 \mathrm{~h}$ the agglomeration rate increases linearly with shear rate. This means that the increase in collision rates as a result of higher shear rates is enough to overcome the lower sticking efficiency. As time progresses a peak develops for the intermediate shear rate, $275 \mathrm{~s}^{-1}$. This is due to lower collision rates in the low shear regime and breakage in the high shear regime as discussed previously. There is also a relatively larger drop in sticking efficiency with time for the lower shear rates compared to higher ones (see Fig. 4). This indicates that growth will slow even more rapidly for low shear rates as time progresses. These findings have positive implications for application in size selective fracture blocking: lower wall shear rates (as found in smaller fractures) will result in both lower collision rates (Eq. 7) and a more significant drop in sticking efficiency as shown in Fig. 4.

DLVO theory describes electrochemical sticking by adding the repulsive forces, arising from a common particle surface charge called the zeta potential, and the attractive forces, arising from Van der Waals interactions between particles of the same type (Elimelech et al. 1995). Both the

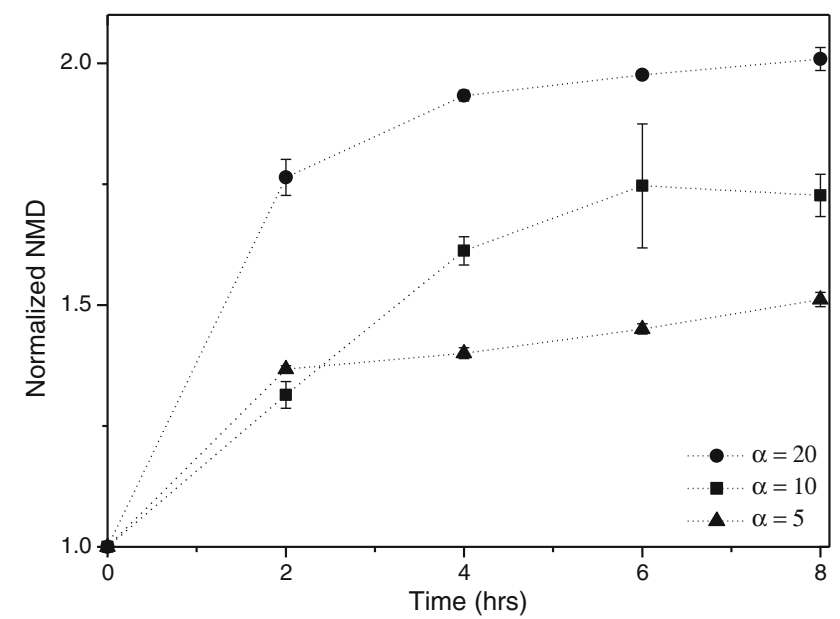

Fig. 6 Normalized number mean diameter for $0.25 \mathrm{~g} / \mathrm{l}$ of Baracarb-5 at different solution supersaturations after shearing for $8 \mathrm{~h}$ at $\gamma=275 \mathrm{~s}^{-1}$

sign and magnitude of the zeta potential is a function of the solid material and solution pH. Yates et al. (2008) found that hetero-agglomeration, between two different mineral types, resulted in larger particles than homo-agglomeration studied here. This is due to the differences in magnitude and sign of the zeta potential between two different mineral types which lead to improved sticking efficiency. A similar phenomenon can be seen in dishwashers where lime-scale deposits on glassware. Due to the opposite zeta potential surface charges of $\mathrm{CaCO}_{3}$ and $\mathrm{SiO}_{2}$ in the dishwasher environment (Fuerstenau 1976), electrochemical attractions promote sticking of precipitated $\mathrm{CaCO}_{3}$ on glass resulting in the white coating often seen. The manipulation of these charges in subsurface environments through changes in the $\mathrm{pH}$ and ionic concentrations can be used to force particle-wall sticking. This is applicable to fractured granite reservoirs, composed of mostly silicates, where a zeta potential difference would exist between the fracture surface and $\mathrm{CaCO}_{3}$ particle.

\section{Supersaturation/precipitation}

Figure 6 shows the effect of varying the solution supersaturation. At higher supersaturations the particle growth is faster and reaches larger final particle sizes. This is due to the availability of the solvated $\mathrm{Ca}^{2+} / \mathrm{CO}_{3}{ }^{2-}$ in the supersaturated solution which forms the "glue" for enabling colliding particles to stick. At a higher supersaturation there are more ions in solution. However, the particle mass concentration remains the same. There is therefore more "glue" per unit surface area in the form of ions available to precipitate out and form interparticle connecting bridges. For the same particle concentration, but with more ions in the solution, the mass of solute depositing from solution 


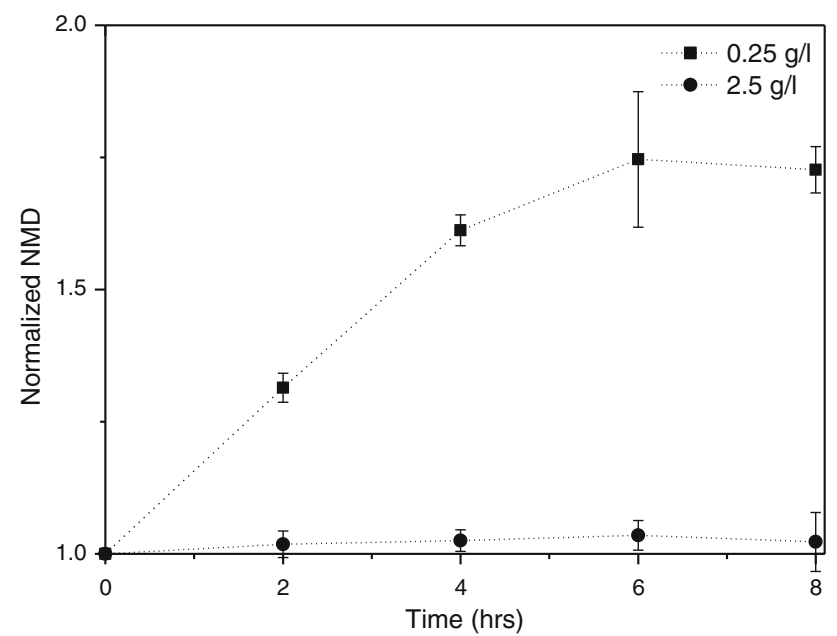

Fig. 7 Normalized number mean diameter for different concentrations of Baracarb-5 at 0.25 and $2.5 \mathrm{~g} / \mathrm{l}$ and $\alpha=10$

has a correspondingly larger effect. The same effect is found for lower particle number concentrations at constant supersaturation. Figure 7 shows Baracarb-5 particle growth for two different mass concentrations, 0.25 and $2.5 \mathrm{~g} / \mathrm{l}$. In this case the number of particles in the $2.5 \mathrm{~g} / \mathrm{l}$ system is 10 times higher than that in the $0.25 \mathrm{~g} / \mathrm{l}$. The growth for lower concentration is faster and reaches a larger final size due to the higher ion to surface area ratio.

If we consider the effect of size on particle agglomeration using Eqs. 2 and 3, for the same mass in solution, the rate of collision of particle size $d_{i}$ differs by a factor of $\left(\frac{d_{j}}{d_{i}}\right)^{3}$ compared to that for particle size $d_{j}$. This is because of the higher number concentration of smaller particles. To test this $0.25 \mathrm{~g} / \mathrm{l}$ of Baracarb-2 and -5 were sheared separately at the same supersaturation condition, $\alpha=10$. These results are shown in Fig. 8 where initially the Baracarb-2 agglomerates at a faster rate due to the higher collision rate. As time progresses however Baracarb-5 results in greater agglomeration compared to Baracarb-2. This is due to the reduced surface area-to-mass ratio for larger particles compared to smaller ones which leads to a higher ion to surface area ratio.

When applied to reservoir applications, these findings indicate that manipulation of the chemical environment can be a means to enhance particle-particle and particle-wall sticking. Future investigation into solid surface charges through ion concentration coupled with $\mathrm{pH}$ manipulation is expected to further improve sticking.

\section{Conclusion}

1. Smaller size distributions agglomerate faster than larger ones.

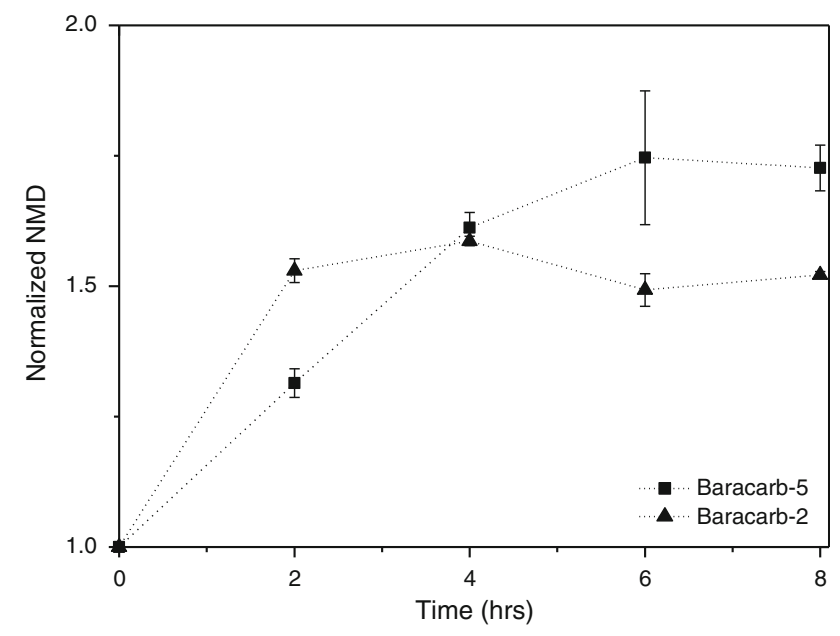

Fig. 8 Normalized number mean diameter for Baracarb-2 and Baracarb-5 showing the effect of particle size on agglomeration at $0.25 \mathrm{~g} / \mathrm{l}$ and $\alpha=10$

2. The hydrodynamic effects formalized by Smoluchowski are supported below a critical shear rate of $275 \mathrm{~s}^{-1}$ after which breakage dominates. (The shear process arising from stirring increases the collision rate.)

3. Low particle number-concentration suspensions agglomerate faster than higher ones when considering the critical role of ion precipitation. This contradicts Smoluchowski's theory which does not take agglomeration chemistry into consideration.

4. The sticking efficiency is a function of the particle/ fluid chemistry. Factors such as surface charge and supersaturation govern these effects.

5. Selective agglomeration controlled by shear rate and chemistry manipulations can thus be induced in particles flowing in the subsurface. The rates we found were too low and final particle size too small for immediate practical use.

6. Hetero-agglomeration (i.e. between two different mineral types) would result in larger particles than the homo-agglomeration studied here. This is the subject of current investigations as exemplified by application of dishwasher phenomena discussed above.

Open Access This article is distributed under the terms of the Creative Commons Attribution License which permits any use, distribution, and reproduction in any medium, provided the original author(s) and the source are credited.

\section{References}

Balakin B, Hoffman A, Kosinski P (2012) The collision efficiency in a shear flow. Chem Eng Sci 68:305-312

Brown D, DuTeaux R, Kruger P, Swenson D, Tsutomu Y (1999) Fluid circulation and heat extraction from engineered geothermal reservoirs. Geothermics 28:553-572 
Chilingarian G, Robertson J, Kumar S (1989) Surface operations in petroleum production. In: Chilingarian $\mathrm{G}$ (ed) Developments in petroleum science. Elsevier, Amsterdam

Colomer J, Paters F, Marrase C (2005) Experimental analysis of coagulation of particles under low-shear flow. Water Res 39:2994-3000

Elimelech M, Gregory J, Jia X, Williams RA (1995) Particle deposition and aggregation. Butterworth-Heinemann, Oxford

Fuerstenau MC (1976) Flotation, vol 1. American Institute of Mining, Metallurgical and Petroleum Engineers Inc, New York

Hollander E, Derksen JJ, Bruinsma OSL, van den Akker HEA, van Rosmalen GM (2003) A numerical study on orthokinetic agglomeration in stirred tanks. Powder Tech 130:169-173

Hounslow M, Andreassen JP (2004) Growth and aggregation of vaterite in seeded-batch experiments. AIChE J 50(11):2772-2782

Huang Y, Fowkes F, Lloyd T, Sanders N (1991) Adsorption of calcium ions from calcium chloride solutions onto calcium carbonate particles. Langmuir 7:1742-1748

Ilievski D, Livk I (2006) An agglomeration efficiency model for gibbsite precipitation in a turbulently stirred vessel. Chem Eng Sci 61:2010-2022

Livk I, Ilievski D (2007) A macroscopic agglomeration kernel model for gibbsite precipitation in turbulent and laminar flows. Chem Eng Sci 62:3787-3797

Moes H, Flash R (2013) Advances in particle size analysis by laser obscuration time. http://www.rktech.hu/dokumentaciok/Ambi Value/Poster/EyeTech_Poster.pdf
Mumtaz H, Hounslow M (2000) Aggregation during precipitation from solution: an experimental investigation using Poiseuille flow. Chem Eng Sci 55:5671-5681

Mumtaz H, Hounslow M, Seaton N, Paterson W (1997) Orthokinetic aggregation during precipitation: a computational model for calcium oxalate monohydrate. Trans IChemE 75(A):152-159

Sanchez Perez J, Rodriguez Porcel E, Casas Lopez J, Fernandez Seville JCY (2006) Shear rate in stirred tank and bubble column bioreactors. Chem Eng J 124:1-5

Rashchi F, Xu ZFJ, Finch JA (1998) Adsorption on silica in $\mathrm{Pb}$ - and $\mathrm{Ca}-\mathrm{SO}_{4}-\mathrm{CO}_{3}$ systems. Colloids Surf A: Physiochem Eng Aspects 132:159-171

Schechter R (1992) Oil well stimulation. Prentice Hall, Eaglewood Cliffs

Smith W, Shlyapubersky J (2000) Basics of hydraulic fracturing. In: Economides M, Nolte K (eds) Reservoir stimulation. Wiley, Chichester

Smoluchowski M (1917) Mathematical theory of the coagulation of colloidal solutions. Z Phys Chem 92:129-168

Yates P, Franks G, Jameson G (2008) Orthokinetic heteroaggregation with nanoparticles: effect of particle size ratio on aggregate properties. Colloids Surf A: Physiochem Eng Aspects 326:83-91

Zimmerman R, Bodvarsson G (1996) Hydraulic conductivity of rock fractures. Transp Porous Med 23:1-30 